\title{
Resource-saving technology of sterilization of grape compote in glass jars 1-82-1000 using multilevel high-temperature mode with heat recovery and its hardware
}

\author{
M.E. Akhmedov ${ }^{1,2, *}$, M.M. Rakhmanova ${ }^{1}$, A.F. Demirova ${ }^{1,2}, Z . A$. Abdulkhalikov $^{2}$, and T.N. \\ Daudova $^{2}$ \\ ${ }^{1}$ FSBRE "Federal Agricultural Research Center of the Republic of Dagestan", Makhachkala, Russia \\ ${ }^{2}$ FSBEO HE "Dagestan State Technical University", Makhachkala, Russia
}

\begin{abstract}
The results of research on the development of a new method of thermal sterilization of canned products with heat recovery and the design of the device for its implementation are presented. The shortcomings of the traditional sterilization regime have been studied and identified, and taking them into account, the regime of multilevel high-temperature thermal sterilization of grape compote in SCO 1-82-1000 glass jars with heat recovery, which provides the required level of industrial sterility and reduces the duration of heat treatment, has been developed. The device for multilevel high-temperature heat treatment has been designed. The developed technology has advantages, being that the product is heated from the entry temperature level to almost $90-93^{\circ} \mathrm{C}$ with the simultaneous cooling from 100 to $63-65^{\circ} \mathrm{C}$ carried out by heat exchange between the very glass jars with different temperatures, which appear simultaneously in the chambers with a heat carrier, the temperature of which for some is higher and for others is lower by $25-27^{\circ} \mathrm{C}$.
\end{abstract}

\section{Introduction}

The level of technical equipment is a determining factor in the efficiency of operation of vegetable-processing and canned long-term storage food producing enterprises, which, combined with advanced innovative technologies, can help improve the competitiveness of their products [1-6].

The technologies used in food enterprises are characterized by high energy intensity, which is in many ways the root cause of the low competitiveness of the products, which naturally calls for a significant change in the structure of technologies based on the introduction of energy-saving processes [1-5].

Based on the evaluation of individual stages of grape compote technology, it can be seen that the final thermal treatment phase, carried out in the devices of various structures, is both

\footnotetext{
*Corresponding author: niva1956@mail.ru
} 
the longest and the most energy-intensive. Moreover, many well-known drawbacks are characteristic of all the designs of heat treatment devices used in practice.

The goal of the research. The goal of the research is to develop an energy-saving method of thermal sterilization and to develop the design of the device for its implementation.

Research tasks. To achieve this goal, the following tasks must be performed:

- study of traditional modes of thermal sterilization;

- development of a new way of thermal sterilization

- development of the design of a device implementing a new method of thermal sterilization.

\section{Materials and methods of research}

The object of the study are the grape compote and the technology of its production, with special attention paid to the process of thermal sterilization.

Experimental studies on the sterilization process were carried out at an experimental installation that allowed to simulate the process under study in the laboratory. An important parameter characterizing the sterilization process is the temperature of the product, which was measured using a $\mathrm{Cr}-\mathrm{Ni}$ and $\mathrm{Cu}-\mathrm{Ni}$ thermocouple connected to the recording potentiometer KSP 4. The development of the pasteurization regime was carried out based on the heating rate graphs, taking into account the value of the required lethality [7].

\section{Research results}

The thermal processing technology implemented based on the traditional technology is based on the fact that after reaching a certain temperature impact, the product is cooled and the heat removed from it by the cooling heat carrier is released into the environment.

An important approach, the implementation of which can provide a significant reduction in the energy intensity of the sterilization process, is to find a technical solution allowing to utilize heat emitted from cooled cans with the product for reuse during the heat treatment of newly supplied cans with the product.

Implementation of this method is an important technical solution to the issue of resource-saving and production of competitive products in the domestic and foreign markets.

Preliminarily, we have investigated the traditional mode of sterilization [8] $\frac{25-25-25}{100} \cdot 118 \mathrm{kPa}$, where: 25,25 and 25 are durations of stages of heating, own sterilization and cooling, minutes; 100 is the temperature level, ${ }^{\circ} \mathrm{C} ; 118$ is anti-pressure, kPA. Studies have confirmed both the long duration and the clearly uneven heating of certain layers of the product in the jar.

To implement a new scientific and technical solution, we have developed a new design of the device for sterilization (Figure 1) [9], an important design solution in which is that it carries out a multilevel, consecutive thermal treatment, and into sterilization chambers with a heat carrier of a certain temperature at the same time arrive jars with the product having undergone heat treatment with a temperature greater than the temperature of the heat carrier in each chamber by $25-27^{\circ} \mathrm{C}$ and jars with the product with a temperature less than the temperature of the heat carrier by $25-27^{\circ} \mathrm{C}$. 


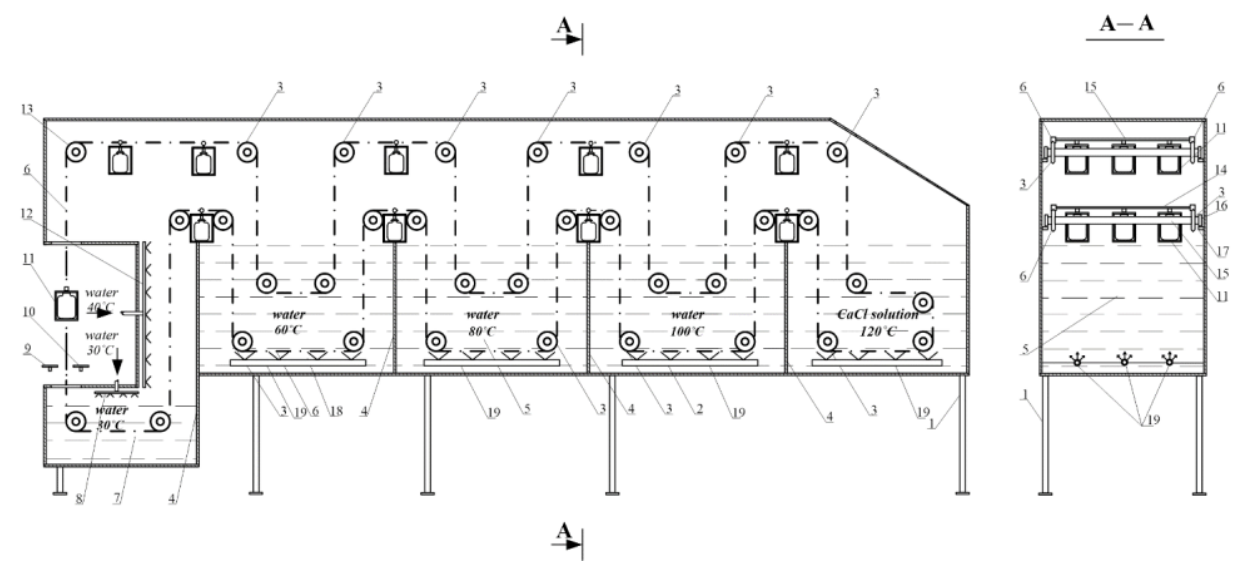

Fig. 1. Design of the device for multilevel high-temperature heat treatment. It contains a frame 1 , heating elements 2 , sprockets 3 , separators 4 , baths for heating and cooling 5 and 18 , Gall's chain 6 , bath for cooling 7; showers 8 and 12 , inbound transporter for cans 9 , outbound transporter for cans 10 , can carriers 11 , a drive sprocket 13 , shafts 14 , guides 15 , bearings 16 , and corners 17 .

The device operates in the following sequence. The transporting organ of the device moves intermittently and during its stops, into the carriers, hinge fixed to the Gall's chain, from the receiving table jars with the product are fed. Transporting body 6 together with the jars enters the first chamber with a hot heat carrier (water) with a temperature of $60^{\circ} \mathrm{C}$; into the same chamber arrive jars with a product from the second chamber with a temperature of $80-85^{\circ} \mathrm{C}$ and due to the heat exchange between these jars with the product, the first ones heat up while the second ones cool down. Then the first (heated) jars arrive in the second chamber with a heat carrier with a temperature of $80^{\circ} \mathrm{C}$, and by the top row into the same chamber arrive jars with the product from the third chamber with a heat carrier at $100^{\circ} \mathrm{C}$ and due to the heat exchange between them, the first are heated to $75-76^{\circ} \mathrm{C}$, and the second cooled to $80-85^{\circ} \mathrm{C}$.

Then the jars with the product arrive sequentially in the fourth and fifth chambers, and the fifth chamber uses a liquid high-temperature heat carrier (dimethyl sulfoxide solution) as a heat carrier, which only carries out the process of heating the product from $93-95^{\circ} \mathrm{C}$ to $100^{\circ} \mathrm{C}$. The fifth chamber filled with calcium chloride solution is used for heating while the first chamber filled with water with a temperature of $40^{\circ} \mathrm{C}$ is used for cooling. The design of the device, made with the ability to move cooled cans on the bottom row, also contributes to the intensification of the natural circulation of the heat carrier in the chambers.

The heat is consumed only in the fifth chamber for the product heating from $93-95^{\circ} \mathrm{C}$ to $100^{\circ} \mathrm{C}$ and for the heat loss to the environment; heat carrier water is consumed only in the first chamber to reduce the temperature of the product from $60-65^{\circ} \mathrm{C}$ to $40^{\circ} \mathrm{C}$.

By changing the temperature parameters of the process, we can facilitate savings of heat and water of more than $80 \%$.

These results allowed to develop new sterilization regimes with heat recovery.

Charts of temperature changes and death rate of microorganisms during multilevel hightemperature sterilization of grape compote in 1-82-1000 glass jars following the mode: $\left(\frac{8}{60^{\circ} \mathrm{C}}\right.$. $\left.\frac{8}{80^{\circ} \mathrm{C}} \cdot \frac{8}{100^{\circ} \mathrm{C}} \cdot \frac{4}{110^{\circ} \mathrm{C}}\right) \cdot\left(\frac{8}{100^{\circ} \mathrm{C}} \cdot \frac{8}{80^{\circ} \mathrm{C}} \cdot \frac{8}{60^{\circ} \mathrm{C}} \cdot \frac{8}{40^{\circ} \mathrm{C}}\right)$, are shown in Figure 2, where 8,8 , and 8 are durations of heating of the product in the chambers at the temperature of the heat carrier (water) of, respectively, 60,80 and $100^{\circ} \mathrm{C}$, min; 4 is the duration of heating of the product in the chamber at the temperature of the heat carrier (dimethyl sulfoxide solution) of $110^{\circ} \mathrm{C}$, min; $8,8,8$, and 8 are durations of exposure at $100^{\circ} \mathrm{C}$ and cooling at the temperature of the heat carrier of, respectively, 80,60 and $40^{\circ} \mathrm{C}$, min. 


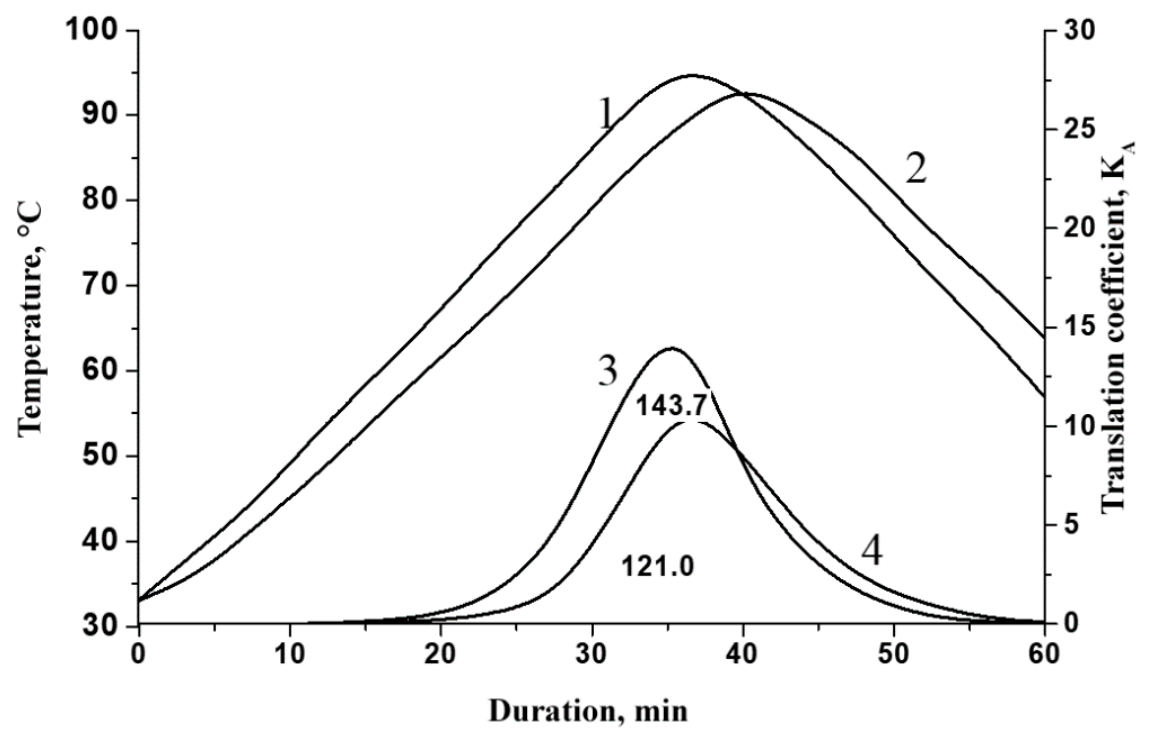

Fig. 2. Charts of temperature change $(1,2)$ and death rate of microorganisms $(3,4)$ in the wall $(1,3)$ and central $(2,4)$ areas during sterilization of grape compote in 1-82-1000 glass jars according to the multilevel high-temperature mode with heat recovery.

The developed method has the advantage of heating the product from the entry level to almost $90-93^{\circ} \mathrm{C}$ with simultaneous cooling from 100 to $63-65^{\circ} \mathrm{C}$ by heat exchange between the very glass jars with different temperatures, which arrive simultaneously into the chambers with the heat carrier, the temperature of which is higher for some and lower for others by 25 $27^{\circ} \mathrm{C}$. Moreover, the temperature difference equal to $25-27^{\circ} \mathrm{C}$ is chosen taking into account the prevention of thermal breakage of the glass jars.

\section{Conclusions}

The obtained results confirm the effectiveness of the proposed method of thermal sterilization $[10,11]$ of canned products with heat recovery. The developed design of the device, the method and modes of sterilization can be proposed for implementation at canning factories.

\section{References}

1. M.D. Mukailov, N.A. Ulchibekova, T.A. Isrigova, M.E. Akhmedov, U.A. Selimova, International Journal of Advanced Science and Technology (2020)

2. T.A. Isrigova, M.M. Salmanov, M.D. Mukailov, T.N. Ashurbekova, U.A. Selimova, Research Journal of Pharmaceutical, Biological and Chemical Sciences RJPBCS, N7(2), 2036-2043 (2016)

3. M. Akhmtdov, A. Demirova, V. Piniaskin, R.A. Rakhmanova, New technological and technical solutions in dietary pear compote production, E3S Web of Conferences, 161 (2020) 
4. M. Akhmtdov, A. Demirova, Z. Abdulkhalikov, T. Daudova, L. Daudova, An enhanced technology of pear compote production through direct blanching with syrup in glass jars and a device for its implementation, E3S Web of Conferences, 161 (2020)

5. V.P. Babarin, Sterilization of canned products 312 (St. Petersburg: GIORD, 2006)

6. C.M.G.C. Renard, J.F. Maingonnat, Thermal processing of fruits and fruit juices, Thermal Food Processing: New Technologies and Quality Issues, 413-440 (Taylor \& Francis, 2012)

7. B.L. Flaumenbaum, S.S. Tanchev, M.A. Grishin, Basics of food sterilization, 264 (M., Agropromizdat, 1986)

8. Collection of technological instructions for the production of canned goods, 2, 355 (M., Piszcprom, 1977)

9. T.A. Ismayilov, A.F. Demirova, M.E. Akhmedov, M.M. Akhmedova, A device for hightemperature thermal sterilization of canned products, (Pat. RF No. 2604919, Bull. No. $35,20.12 .2016)$

10. G.I. Kasyanov, A.F. Demirova, M.E. Akhmedov, Reports of the Russian Academy of Agricultural Sciences, 6, 57-59 (2014) 